\title{
Synaptogenesis and FOS Expression in the Motor Cortex of the Adult Rat after Motor Skill Learning
}

\author{
Jeffrey A. Kleim, ${ }^{1,4}$ Erich Lussnig, ${ }^{4}$ Edward R. Schwarz, ${ }^{4}$ Thomas A. Comery, ${ }^{3,4}$ and \\ William T. Greenough ${ }^{1,2,3,4}$ \\ Departments of ${ }^{1}$ Psychology and ${ }^{2}$ Cell and Structural Biology, ${ }^{3}$ Neuroscience Program, and ${ }^{4}$ Beckman Institute, \\ University of Illinois, Urbana, Illinois 61801
}

\begin{abstract}
Recent work has suggested that changes in synapse number as well as changes in the expression of the Fos protein may occur within the motor cortex in association with motor learning. The number of synapses per neuron and the percentage of Fos-positive neurons within layer II/III of the rat motor cortex was measured after training on a complex motor learning task. Adult female rats were allocated randomly to either an acrobatic condition $(A C)$, a motor control condition (MC), or an inactive control condition (IC). AC animals were trained to traverse a complex series of obstacles, and each AC animal was pair matched with an $M C$ animal that traversed an obstacle-free runway. IC animals received no motor training. Animals from each condition were killed at various points during training, and unbiased stereological techniques were used
\end{abstract}

to estimate the number of synapses per neuron and the percentage of Fos-positive cells within layer II/III of the motor cortex. AC animals exhibited an overall increase in the number of synapses per neuron in comparison to $\mathrm{MC}$ and IC animals at later stages of training. AC animals also had a significantly higher overall percentage of Fos-positive cells in comparison to both controls, with a trend for the increase to be greater during the acquisition versus the maintenance phase. These data suggest that Fos may be involved in the biochemical processes underlying skill acquisition and that motor learning, as opposed to motor activity, leads to increases in synapse number in the motor cortex.

Key words: motor learning; motor cortex; synaptogenesis; Fos; c-fos; synaptic plasticity; rat
Experience can alter the structure and function of cells in the adult CNS (for review, see Bailey and Kandel, 1993; Greenough et al., 1994), and such experience-dependent plasticity may be a neurobiological substrate of memory (Greenough, 1984; Thompson, 1986). Experimental manipulations of experience have shown that increasing the complexity of the housing environment (Volkmar and Greenough, 1972; Turner and Greenough, 1983), maze training (Chang and Greenough, 1982), avoidance conditioning (Patel and Stewart, 1988; Doubell and Stewart, 1994), and sensitization (Bailey and Chen, 1983) result in neuronal growth in a variety of different species.

Several experiments also have demonstrated structural changes within sensorimotor regions of the brain after motor learning. An increase in the number of synapses per Purkinje cell was found in the cerebellar cortex of animals trained to complete a complex motor learning task in comparison to both active and inactive controls (Black et al., 1990; Kleim et al., 1994; Kleim et al., 1995). Similarly, increases in the thickness of some regions of the motor cortex (Anderson et al., 1992) and increases in the dendritic material of motor cortex neurons (Greenough et al., 1985; Withers and Greenough, 1989) have been reported after motor learn-

\footnotetext{
Received Aug. 14, 1995; revised April 12, 1996; accepted April 24, 1996.

This work was supported by National Institutes of Health Grants AG10154, MH40631, MH35321, the Kiwanis, the Retirement Research Foundation, and a Natural Science and Engineering Research Council of Canada fellowship. We thank David Ballard, Kara Federmeier, and Kapil Vij for assistance in training the animals and printing the micrographs; the Beckman Institute Optical Visualization Facility for use of its stereology system; the University of Illinois Center for Electron Microscopy for the use of its facilities; and Theresa Jones and Rodney Swain for their comments on this manuscript.

Correspondence should be addressed to William T. Greenough, Beckman Institute, University of Illinois, 405 North Mathews Avenue, Urbana, IL 61801.

Copyright (C) 1996 Society for Neuroscience $0270-6474 / 96 / 164529-07 \$ 05.00 / 0$
}

ing, suggesting that learning-related synaptogenesis also may occur in the motor cortex.

Such structural change should require the synthesis and/or redistribution of various neuronal proteins, and several studies have demonstrated increased protein synthesis after behavioral training (Pohle et al., 1979; Miluesnic et al., 1980; Bullock et al., 1987; Rose, 1989; Kuhl et al., 1992). Furthermore, various protein and RNA synthesis inhibitors can have amnesic effects if given near the time of training (Agranoff et al., 1965; Flexner et al., 1967) and can prevent training-induced changes in neuronal morphology (Bradley and Galal, 1987; Bailey et al., 1992). The specific mechanisms by which experience could influence neuronal structure remain to be determined. A recent hypothesis suggests that cell stimulation may affect protein synthesis via "immediate-" or "early-" response transcription factor genes. The protein products of the immediate early genes (IEGs) would in turn act to regulate the expression of "late" genes involved in producing long-term modifications in cell structure/function (Sheng and Greenberg, 1990). The IEG c-fos encodes the nuclear phosphoprotein Fos that binds DNA as a heterodimer with the protein Jun. Fos is expressed within minutes after a variety of electrophysiological and pharmacological stimulation paradigms (for review, see Robertson, 1992) as well as after training on a number of different learning paradigms (Campeau et al., 1991; Bialy et al., 1992; Castro-Alamancos et al., 1992; Heurteaux et al., 1993). Traininginduced increases in c-fos expression also have been reported in regions of the developing chick brain shown to undergo experience-related changes in neuron structure (Anokhin and Rose, 1991; Ambalavanar et al., 1993).

In the present experiment, learning-related changes in Fos expression and synapse number were examined using a behavioral 
paradigm that allowed for the separation of changes attributable to motor learning versus motor activity.

\section{MATERIALS AND METHODS}

Behavioral training. Seventy-five female Long-Evans hooded rats (Simonsen Labs) were housed two to three per cage until $\sim 3$ months of age when they were allocated randomly to one of three training conditions in a manner that distributed littermates equally across groups. The acrobatic condition (AC) $(n=25)$ animals were trained (three trials/day) on an obstacle course for which successful completion required a substantial amount of motor coordination. On each trial, the animals were required to traverse 10 different obstacles including a rotating cylinder, dowel rods of varying diameters, a suspended chain, wooden blocks, and various other obstacles. To keep the animals moving through the course, they were occasionally prodded gently on the hindquarters by the experimenter. Animals received a prod immediately on stopping during any given task, and the animals were prodded until they began to continue along the task. In previous experiments, it has been found that the number of foot faults as well as the number of prods declines progressively in the AC animals during training, which is reflected in a progressive reduction in the mean time/task (Kleim et al., 1994). In the present experiment, only the time required to complete each task on each trial was recorded. Each AC animal was pair matched with an animal in the motor control condition (MC). The MC animals were forced to traverse a flat, Plexiglas runway equal in length to the acrobatic course. The runway was located next to the acrobatic course, separated by a curtain. Each MC animal was yoked to its AC littermate. Both animals were placed onto their respective courses at the same time and removed when the AC animal had finished all three trials. During training, when an AC animal received a prod, an experimenter also would prod the paired MC animal simultaneously such that both animals received comparable amounts of stimulation. Inactive condition (IC) animals were housed individually and received no motor training or extra-cage motor activity but were handled for $\sim 4$ min each day. Before the beginning of training, five animals from each of the three groups were allocated randomly to be killed after $1,2,5,10$, and $20 \mathrm{~d}$ of the manipulation.

\section{Electron microscopy}

Tissue preparation. One hour after the training session, animals were anesthetized with pentobarbital $(120 \mathrm{mg} / \mathrm{kg})$ and perfused transcardially with $4 \%$ paraformaldehyde in $0.1 \mathrm{~m}$ phosphate buffer (PB), $\mathrm{pH}$ 7.4. Brains were removed immediately from the cranium and half of the cerebrum (left and right hemispheres being equally represented in all groups) was sectioned coronally $(300 \mu \mathrm{m})$ on a vibratome within $1 \mathrm{hr}$ of perfusion. The remaining half of the cerebrum was used for immunohistochemical examination of the Fos protein. Sections were taken through primary motor cortex (MI) (+1.6 to $-1.4 \mathrm{~mm}$ to bregma), which was identified using subcortical landmarks (Hall and Lindholm, 1974; Wise and Donoghue, 1986). From these sections, blocks of motor cortex extending from pia to white matter were removed under a dissection microscope. These blocks of tissue then were post-fixed in $2 \%$ glutaraldehyde in $0.1 \mathrm{M}$ cacodylate buffer overnight at $4^{\circ} \mathrm{C}$. The tissue blocks then were washed in $0.1 \mathrm{M}$ cacodylate, post-fixed in $2 \%$ osmium tetroxide $/ 1.5 \%$ potassium ferrocyanide in $0.1 \mathrm{M}$ cacodylate buffer for $2 \mathrm{hr}$ and en bloc stained with $2 \%$ uranyl acetate for $45 \mathrm{~min}$. The tissue samples then were dehydrated through a series of alcohols before being transferred into propylene oxide and embedded gradually in Medcast resin. Because of poor tissue fixation, six animals had to be removed from the anatomical analysis.

Stereological methods. Previous experiments have shown that experience can lead to the addition of synapses as well as to an increase in the volume of neuropil in which these synapses exist (Rosenzweig et al., 1962; Turner and Greenough, 1985; Anderson et al., 1992). Because of this volume increase, measures of synapse density alone may not reveal changes in synapse number. In conditions of stable neuron number, however, estimates of the number of synapses per neuron reflect changes in synapse number accurately (Anker and Cragg, 1974). By obtaining neuronal density per unit volume and synapse density per unit volume, the number of synapses per neuron can be calculated and used to measure changes in synapse number (Turner and Greenough, 1983; Black et al., 1990).

Neuron density. One block from each animal was chosen randomly and 40 serial, $1 \mu \mathrm{m}$ sections were taken using a glass knife and an ultramicrotome (Sorvall MT-1). These sections were stained with toluidine blue, and cortical layer II/III was identified. Using a computer-assisted micro- scope and a stereology software package (Phokus on Stereology, Beckman Institute Visualization Facility), the physical disector (Sterio, 1984) was used to obtain a measure of neuron density. This method involves comparing two serial sections, the first of which is considered the reference section and the second the lookup section. Within an unbiased counting frame of a known area, the number of nuclei that are present in the reference section but not the lookup section $\left(\mathrm{Q}^{-}\right)$are counted. The disector volume of tissue through which the cells are counted $\left(V_{\text {dis }}\right)$ is given by:

$$
V_{\text {dis }}=\left(A_{\text {frame }}\right)(H),
$$

where $A_{\text {frame }}$ is the area of the counting frame and $H$ is the section thickness multiplied by the number of sections. The neuronal density $\left(N v_{\text {neuron }}\right)$ then is determined by:

$$
N v_{\text {neuron }}=\frac{Q^{-}}{V_{\text {dis }}} .
$$

This method allows for an accurate estimation of cell density that is unbiased with respect to cell size and shape.

Synapse density. After the $1 \mu \mathrm{m}$ sectioning, a small pyramid was trimmed into layer II/III of the motor cortex using a $1 \mu \mathrm{m}$ toluidine blue section from that block as a guide. From the pyramid, 16 silver-gray serial sections $(\sim 70 \mathrm{~nm}$ thick) were taken using a diamond knife and an ultramicrotome (Reichert Ultracut S). Sections were collected on Formvar-coated, slotted copper grids and stained with lead citrate. One micrograph (22 $000 \times$ print magnification) was taken from the same position in each section for a total of 16 micrographs per animal, using a JEOL 100C electron microscope. Synapses were identified by the presence of a postsynaptic density and at least three vesicles in the presynaptic element. The physical disector method again was used to determine synapse density for which the number of synapses present in the reference section but not the lookup section was counted $\left(\mathrm{Q}^{-}\right)$through a known volume of tissue $\left(V_{\mathrm{dis}}\right)$ (Fig. 1). The number of synapses per neuron then was obtained by dividing the density of synapses per cubic millimeter by the density of neurons per cubic millimeter.

\section{Immunohistochemistry}

Tissue preparation. One hour after training, animals were anesthetized with pentobarbital $(120 \mathrm{mg} / \mathrm{kg})$ and perfused transcardially with $4 \%$ paraformaldehyde in $0.1 \mathrm{M} \mathrm{PB}, \mathrm{pH}$ 7.4. Brains were removed immediately from the cranium, and half of the cerebrum (left and right hemispheres being equally represented in all groups) was post-fixed in the above fixative at $4^{\circ} \mathrm{C}$. Tissue samples were cryoprotected for $48 \mathrm{hr}$ in a sodium phosphate buffered $(0.1 \mathrm{M}) 30 \%$ sucrose solution and frozen in dry ice before coronal sections $(60 \mu \mathrm{m})$ were taken through the motor cortex ( +1.6 to $-1.4 \mathrm{~mm}$ to bregma) using a sliding microtome.

Immunohistochemistry. Using the free-floating method, eight sections per animal first were transferred into small perforated, polyethylene wells containing $0.1 \mathrm{M}$ PBS, $\mathrm{pH} 7.3$, and then placed into a blocking solution ( $2 \%$ horse serum $/ 0.2 \%$ Triton $\mathrm{X}-100 / 0.1 \%$ bovine serum albumin) for 2 $\mathrm{hr}$. The sections then were washed in $0.1 \mathrm{M}$ PBS $(3 \times 5 \mathrm{~min})$ before being incubated for $60 \mathrm{hr}$ at $4^{\circ} \mathrm{C}$ in a solution containing the monoclonal Fos antibody LA041 (the generous gift of Dr. Frank Sharp), diluted 1:10,000 with $0.5 \%$ Triton $\mathrm{X}-100$ and $0.1 \mathrm{M}$ PBS. The antibody was generated against a synthetic peptide (Fos 4-17) from the N-terminal end of the Fos protein and does not recognize Fos-related antigens on Western blot analyses (De Togni et al., 1988). Sections then were washed $(3 \times 5 \mathrm{~min})$ in $0.1 \mathrm{M}$ PBS and incubated for $2 \mathrm{hr}$ in biotinylated anti-mouse secondary antibody (Vector Laboratories, Burlingame, CA) 1:200 in 2\% horse serum $/ 0.1 \mathrm{M}$ PBS. Tissue sections again were washed $(5 \times 5 \mathrm{~min})$ in 0.1 M PBS, pH 7.3, and incubated in the Vectastain avidin-biotin complex (Vector Laboratories) for $3 \mathrm{hr}$. After another series of washes $(5 \times 5 \mathrm{~min})$ in $0.1 \mathrm{M}$ PBS, $\mathrm{pH} 7.3$, sections were reacted in a solution containing $0.05 \%$ $3,3^{\prime}$-diaminobenzidine tetrahydrochloride, $0.7 \%$ nickel ammonium sulfate, and $0.01 \% \mathrm{H}_{2} \mathrm{O}_{2}$ in Tris buffer. Sections then were washed $(5 \times 5$ min) in $0.1 \mathrm{M}$ PBS, pH 7.3, and mounted on gelatin-chrom-alum-coated slides and counterstained with the Nissl stain Pyronin Y. Nuclei throughout the thickness of the section appeared to be equally likely to be labeled. All slides then were coded with respect to treatment condition before data collection. As a positive control, one littermate not used in the experiment was given a series of intraperitoneal injections of the GABAergic receptor inhibitor Metrazole $(50 \mathrm{mg} / \mathrm{kg})$. This protocol results in massive seizure activity and leads to the induction of c-fos in several regions of the brain (Morgan et al., 1987). Sections from this 


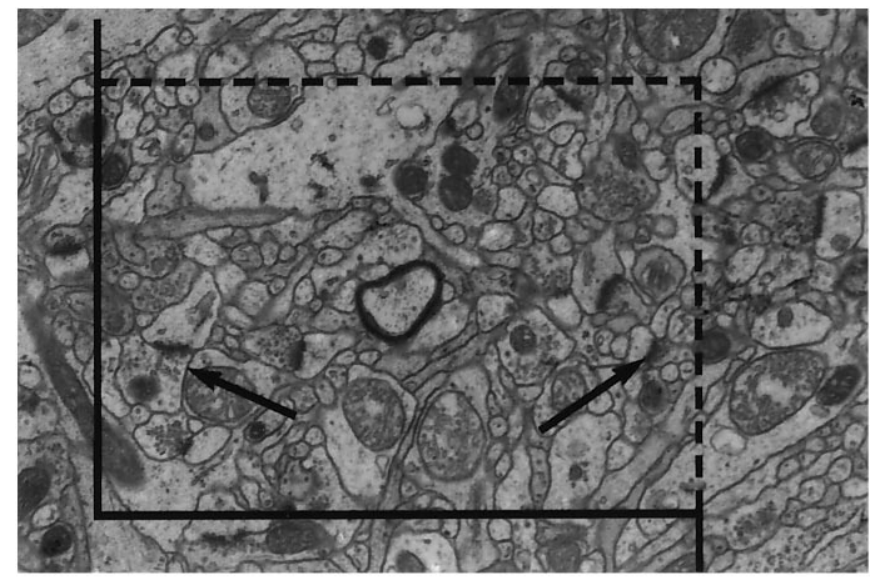

Reference Section

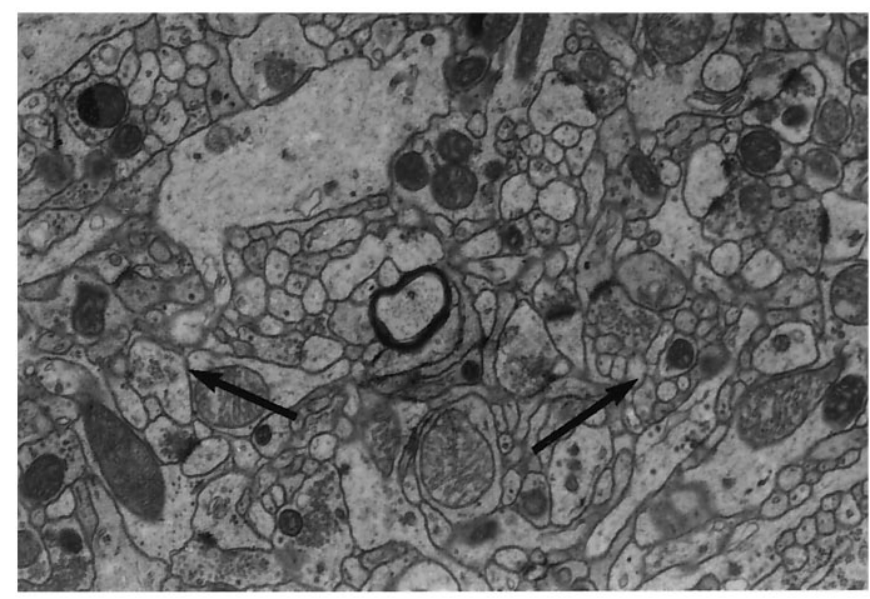

Look up Section

Figure 1. Two serial electron micrographs $(11,000 \times)$ taken within layer II/III of the motor cortex. Synapse density was determined using the physical disector method. Synapses, within an unbiased counting frame, present in the reference section but not the lookup section (arrows), were counted.

animal were processed along with those of the animals used in the experiment. Furthermore, as a negative control, some of the sections from the Metrazole-injected animal also were processed without exposure to the primary antibody.

Quantification. Using a dissection microscope, primary motor cortex (MI) was defined cytoarchitectonically on each section by the disappearance of the layer IV granule cells and the enlargement of layer V (Hall and Lindholm, 1974; Wise and Donoghue, 1986). Layer II/III then was identified and its borders defined on each section with a fine-point marker to prevent sampling outside of this region. Using a computer-assisted microscope and monitor $(1400 \times)$, a modification of the optical disector (Braendgaard et al., 1990) was used to determine the percentage of Fos-positive cells in each animal. An unbiased counting frame was positioned randomly across layer II/III, and at each position the top of the tissue section was defined as the first focal plane where cells came into focus. By adjusting the focus of the microscope slowly, a focal plane was gradually passed through each section. The total number of cells, within the unbiased counting frame, encountered while focusing through the section were counted, as were the number of Fos-positive cells (Fig. 2). Fos-positive cells were identified by the presence of black immunoprecipitate within the cell nucleus surrounded by the pinkish-red Nisslstained cell soma. The amount of immunolabeling ranged from completely blackened nuclei to nuclei with a speckled appearance. Nuclei that appeared to be labeled above that of the background labeling within the neuropil were counted as Fos-positive. The percentage of Fos-positive cells then was determined by:

$$
\% \text { Fos-positive cells }=\frac{(\text { No. Fos-positive cells })}{(\text { Total no. of cells })} \times 100 .
$$

\section{RESULTS}

\section{Behavior}

A one-way ANOVA with DAY as a within-subject factor was conducted on the data from all animals and showed the mean time/task/trial to decrease significantly as training progressed $\left(F_{(19,76)}=27.96, p<0.001\right)$ (Fig. 3), indicating a substantial amount of motor skill acquisition. Previous experiments have shown that this decrease in time reflects the progressive decrease in the number of foot faults committed by the animals on each task (Kleim et al., 1994). Other behavioral changes in the AC animals included a tendency to move on to the next task without hesitation as well as a reduction in the number of prods during the performance of each task. Because of the nature of the acrobatic task and the flat runway, $\mathrm{MC}$ animals tended to travel farther than their AC counterparts. It was found to be difficult to control the distance an MC animal would travel after a single prod. After a single prod, the MC animals tended to move a greater distance down the runway than the $\mathrm{AC}$ animals would along the acrobatic task. Thus, the MC animals traveled a greater total distance than the AC animals on any given trial. This difference was greatest during the early stages of training when the $\mathrm{AC}$ animals required more prodding, but eventually declined as training progressed. No other behavioral changes were observed in the MC animals during training.

\section{Synapses per neuron}

A two-way ANOVA with CONDITION and DAY as betweensubject factors revealed a significant main effect of condition on the number of synapses per neuron $\left(F_{(2,54)}=3.72, p<0.05\right)$ within the motor cortex. Subsequent multiple comparisons (Student-Neuman-Keuls test; $p<0.05)$ revealed that the AC $(8335 \pm$ 320) animals had significantly more synapses per neuron than both the MC (7248 \pm 284$)$ and IC (6782 \pm 273$)$ animals (Fig. 4). To examine any possible effects of training on synapse number, the synapses per neuron data were pooled into an acquisition phase (days 1 and 2) and a maintenance phase (days 5, 10, and 20) based on the behavioral data (Fig. 3). A two-way ANOVA with PHASE and CONDITION as between-subject factors revealed a significant PHASE $\times$ CONDITION interaction $\left(F_{(2,63)}=3.18\right.$, $p<0.05$ ). Multiple comparisons (Student-Neuman-Keuls test; $p<0.05)$ revealed that the $\mathrm{AC}(8877 \pm 546)$ animals had significantly more synapses per neuron during the maintenance phase than both the MC $(7271 \pm 463)$ and IC $(7485 \pm 396)$ animals as well as the AC (7552 \pm 513$), \mathrm{MC}(7210 \pm 397)$, and IC $(6088 \pm 359)$ animals in the acquisition phase (Fig. 4).

\section{Fos expression}

Examination of sections from the animal that received the Metrazole-induced seizure revealed massive Fos expression throughout the brain, whereas sections of this animal that were not exposed to the primary antibody during processing showed no labeling. Approximately $41( \pm 5)$ samples were taken within the motor cortex of each animal, resulting in a total of $158( \pm 9.8)$ cells counted per animal from which the percentage of Fospositive cells was determined. The mean of the individual coefficients of error on this measure was 9.7\%. A two-way ANOVA with CONDITION and DAY as between-subject factors revealed 


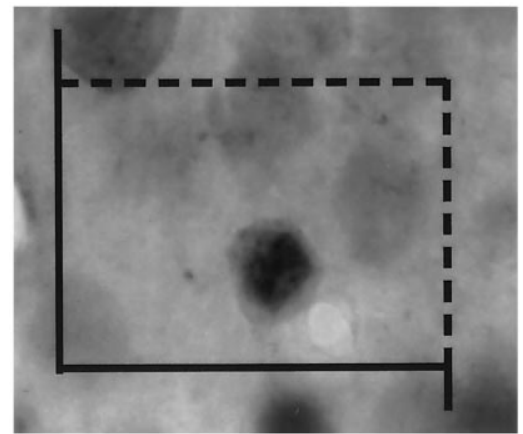

Focal Plane 1

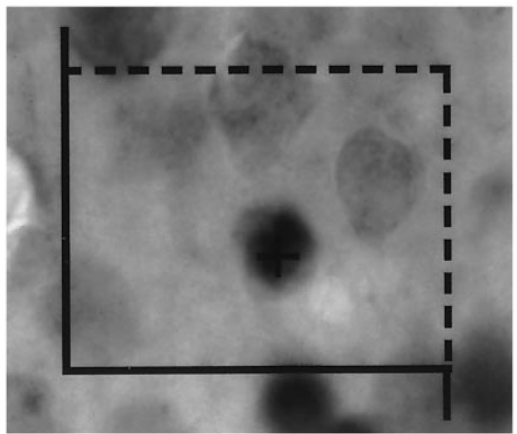

Focal Plane 2

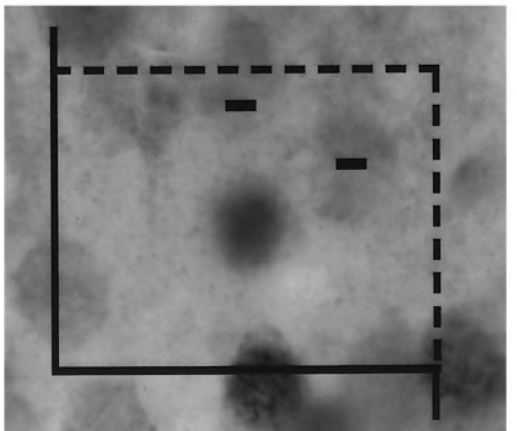

Focal Plane 3

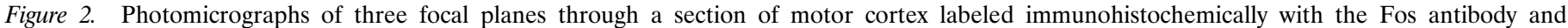

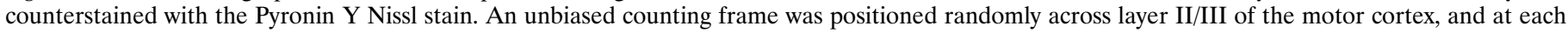

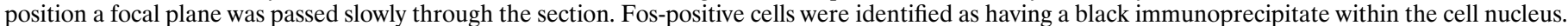
The total number of cells, both Fos-positive $(+)$ and -negative $(-)$, were counted, and the percentage of Fos-positive cells was determined.

a significant main effect of CONDITION on the percentage of Fos-positive cells $\left(F_{(2,59)}=24.87, p<0.001\right)$. Subsequent multiple comparisons (Student-Neuman-Keuls test; $p<0.05$ ) showed the AC animals $(41.1 \%)$ to have a significantly greater percentage of Fos-positive cells within layer II/III than both the MC $(15.8 \%)$ and IC $(11.2 \%)$ groups, which did not differ (Fig. 5). To examine further any training effects on Fos expression, the data were pooled into an acquisition phase (days 1 and 2) and a maintenance phase (days 5, 10, and 20), based on the performance of the animals on the acrobatic task. A two-way ANOVA with PHASE and CONDITION as between-subject factors revealed no significant PHASE $\times$ CONDITION interaction $\left(F_{(2,68)}=1.72, p=\right.$ $0.18)$. A linear trend analysis, however, revealed a significant trend toward a decrease in the percentage of Fos-positive cells across the five time points in the AC condition $\left(F_{(1,4)}=6.62, p<\right.$ $0.05)$, but not in the $\mathrm{MC}\left(F_{(1,4)}=0.39, p=0.54\right)$ or IC conditions $\left(F_{(1,4)}=0.02, p=0.88\right)$ (Fig. 5). An examination of the withinanimal relationship between Fos expression and synapse number revealed a weak positive correlation between the two measures $(r=0.11 ; p>0.05)$

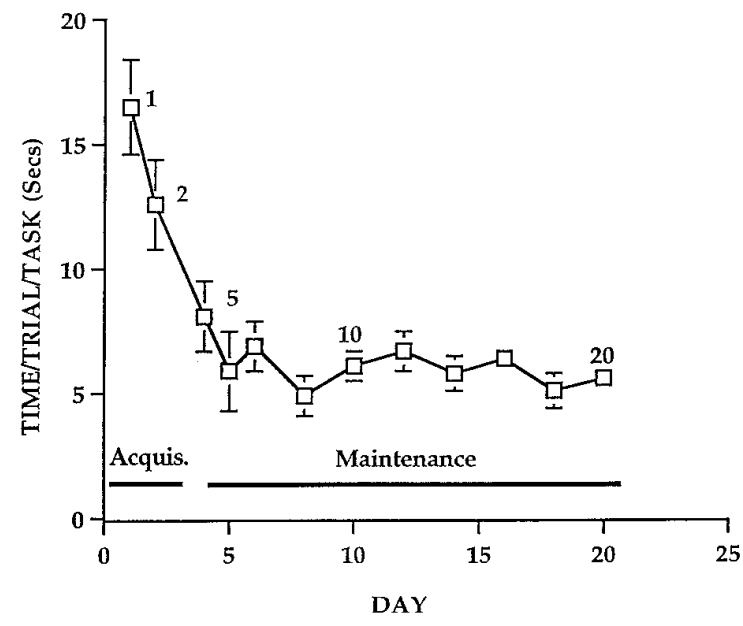

Figure 3. Performance on the acrobatic task ( \pm SEM) for all animals. The mean time/trial/task decreased significantly as training progressed. Numbers indicate days on which animals from each of the three conditions were killed.

\section{DISCUSSION}

Adaptation is one of the fundamental characteristics of all living organisms. There now is considerable evidence that the adaptation of behavior observed after experience is subserved by a structural and functional adaptation of the brain. The present experiment demonstrates further that the type of experience an animal receives can affect differentially the molecular and structural profile of neurons within the brain. Within the motor cortex of animals forced to acquire motor skill, there was a significant increase in the number of synapses per neuron and a transient increase in the percentage of neurons expressing the Fos protein in comparison to both active and inactive controls.

\section{Changes in synapse number}

Recent work has shown that motor learning, and not mere motor activity, is associated with increases in synapse number within the

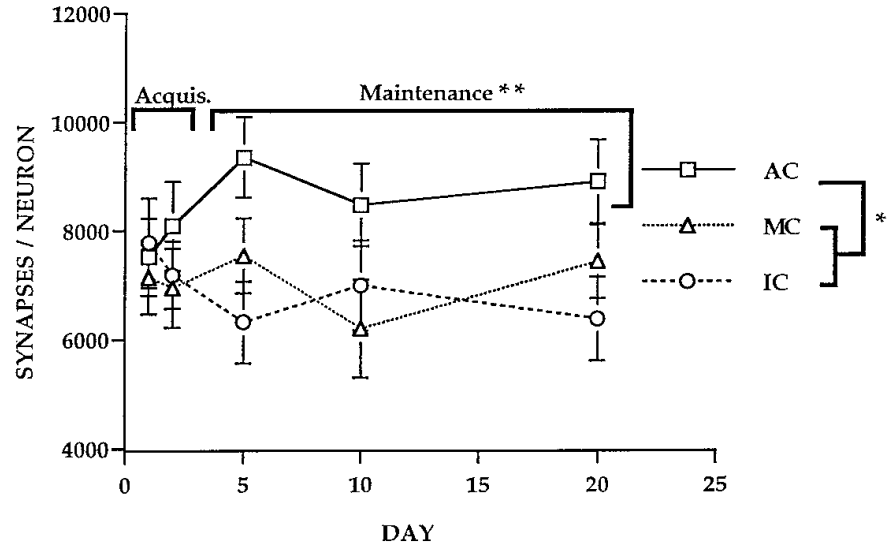

Figure 4. Mean number of synapses per neuron $( \pm$ SEM) within layer II/III of the motor cortex during training as determined by dividing synapse density per cubic millimeter by neuronal density per cubic millimeter. Animals killed on day 1 or $2(A C, n=9 ; M C, n=9 ; I C, n=10)$ were considered to be in the acquisition phase, and animals killed on day 5,10 , or $20(A C, n=13 ; M C, n=15 ; I C, n=13)$ were considered to be in the maintenance phase. Asterisk, AC animals $(n=22)$ had overall significantly more synapses per neuron than both the MC $(n=24)$ and IC $(n=23)$ animals (Student-Neuman-Keuls test; $p<0.05)$; double asterisk, $\mathrm{AC}$ animals during the maintenance phase had significantly more synapses per neuron than all other conditions in either phase (Student-NeumanKeuls test; $p<0.05$ ). 


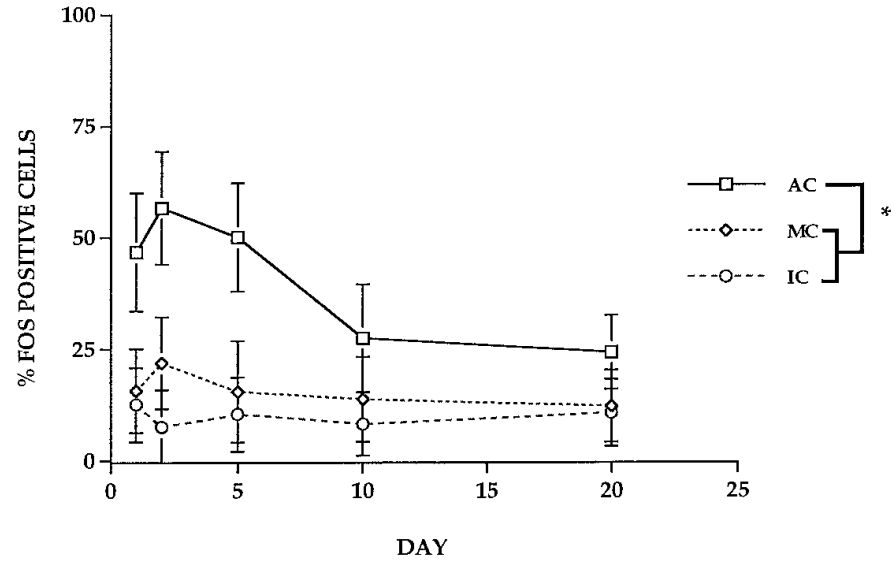

Figure 5. Percentage of Fos-positive cells ( \pm SEM) in all three conditions at five different points during training. Asterisk, AC animals $(n=25)$ had a significantly greater percentage of Fos-positive cells than both the MC $(n=25)$ and IC $(n=24)$ groups. No significant differences were found across the acquisition and maintenance phases of training.

cerebellar cortex (Black et al., 1990; Kleim et al., 1994; Kleim et al., 1995), and this experiment demonstrates a similar finding within the motor cortex. Furthermore, when the synapses-perneuron data were examined in relation to performance on the acrobatic task, the AC animals had significantly more synapses per neuron during the maintenance phase than during the acquisition phase. Layer II/III was chosen for analysis because of previous data showing structural plasticity there after motor skill learning (Withers and Greenough, 1989) and because input from somatosensory cortical areas, which is strong to these layers, is important for novel skill acquisition (Pavlides et al., 1993). Pavlides et al. (1993) proposed a model for motor learning in the motor cortex based on its diffuse inputs from the ventrolateral thalamus (Strick, 1973), as well as the more specific inputs from the somatosensory cortex, both terminating in layer II/III (Porter and Sakamoto, 1988). Pavlides et al. propose that during motor skill acquisition, some of the diffuse projections from the thalamus to the motor cortex become strengthened through a synaptic enhancement that is dependent on somatosensory cortex input and is accomplished through the formation of new synapses (Keller et al., 1992). Recent work suggests a functional correlate of increased synapse number in the form of enhanced postsynaptic responses after motor learning (Yi and Greenough, 1994). Although synapse numbers in this study were obtained within layer II/III, it is difficult to determine how many of the synapses were onto the dendrites of layer II/III neurons rather than onto the apical dendrites from layer $\mathrm{V}$ pyramidal cells that extend up into layer II/III. Furthermore, the presynaptic origin of these synapses was not determined such that this aspect of their model cannot be evaluated. The global nature of this motor learning task may demand the integration of a variety of inputs, and the increased synapse number may well reflect increases in synapses from multiple afferents including those from both thalamic and cortical regions. Long-term potentiation has been observed in both layer II/III (Sakamoto et al., 1987; Yi and Greenough, 1994) and layer V neurons (Kimura et al., 1994), and changes in pyramidal cell dendritic arborizations after motor learning also have been observed in neurons of both layer II/III (Withers and Greenough, 1989) and layer V (Greenough et al., 1985), suggesting that the plastic changes associated with motor learning may be distributed across several layers of the motor cortex.

\section{Changes in Fos expression}

This experiment demonstrates that c-fos expression is elevated in association with motor skill learning and that this increase is not brought about by increased motor activity alone. Nor is its elevation maintained during practice once skill has been acquired. Evidence that Fos activity is not merely a marker for neuronal activity also comes from studies of neuronal activation by seizure (Morgan et al., 1987) or electrophysiological stimulation (Sagar et al., 1988) in which there are some metabolically activated brain areas that lack c-fos expression. Similarly, there also are instances in which c-fos expression is found in the absence of increased metabolic activity (Sagar et al., 1988; Jorgensen et al., 1989). Furthermore, studies have demonstrated that Fos upregulation after post-hatching behavioral training in chicks is not simply attributable to stress or the degree of neuronal activity (Anhokin and Rose, 1991; Anhokin et al., 1991). In the present experiment, cells within layer II/III of the motor cortex responded differently in association with motor skill learning than with simple motor activity. The AC animals had a significantly higher percentage of Fos-positive cells than the MC animals, and there was a progressive reduction in Fos expression in the AC animals during training. It could be argued that the amount of motor activity experienced by the AC animals was greater during the acquisition phase than during the maintenance phase of training, explaining the progressive decline in Fos levels. The AC animals did spend more time on the motor learning task during the early stages of training and may have experienced a slight increase in motor activity during this time. However, if Fos expression was related solely to motor activity, then this same pattern should have been evident in the $\mathrm{MC}$ animals as well. Because the MC animals were pair matched to the AC animals, they to were forced to spend more time on the runway during the early stages of training and therefore also traveled farther during the acquisition phase of the task. There thus appears to be a relationship between the acquisition of the motor skills necessary to complete the task and the increase in Fos levels. Increases in c-fos mRNA have been reported in association with novel versus familiar experience (Anhokin et al., 1991), and the early trials of the motor learning task in this experiment may be considered novel. However, the MC animals similarly are experiencing a novel environment but do not show significant increases in Fos expression early during training. The novelty per se does not appear to be the primary source of the upregulated Fos expression.

Recent work has demonstrated that interfering with the action of at least one transcription factor can affect learning ability. Disrupting the function of the CREB protein, which participates in inducing transcription of the c-fos gene, causes learning impairments in both flies and mice (Bourtchuladze et al., 1994; Yin et al., 1994), whereas enhancing its expression improves memory in Drosophila (Yin et al., 1995). The role the Fos protein may play in the memory process, however, is not clear. It is known that Fos, in conjunction with Jun, acts at the AP-1 DNA binding site to either promote or repress transcription (Chui et al., 1988). Fos may act to promote the transcription of various proteins necessary for changes in neuron structure and function such as nerve growth factor (Hengerer et al., 1990) or to deregulate cytoskeletal proteins to promote morphological transformation (Jooss and Müller, 1995). However, it is unlikely that changes in Fos expression within the cell nucleus would affect selectively the formation of specific synapses out at the dendrites. The cascade of cellular events associated with changes in dendritic structure is most certainly very complex, involving the synthesis, targeting, 
and transport of essential proteins, and Fos induction may represent one early component of this process. Given that the Fos protein is present at basal levels in most cells and has been shown to be increased by a variety of stimulation paradigms, it is most likely involved in cellular processes associated with basic cell functioning that may be simply upregulated during periods of plastic change. In the present experiment, Fos levels were generally high at those points during training before the increase in synapse number and then were reduced after the increase. However, on day 5, both Fos levels and synapse number were increased in the AC animals. This pattern may account for the low correlation between Fos expression and synapse number. If c-fos expression was involved in a subsequent increase in synapse number, the relevant Fos expression may well have regressed before the time of structural remodeling. It would be of interest to examine if the inhibition of c-fos expression would impair the acquisition of motor skill and prevent neuronal remodeling. At least one study has demonstrated that animals lacking a functional c-fos gene are impaired on some learning tasks, but that this may be attributable to gross behavioral impairments rather than to a specific learning deficit (Paylor et al., 1994).

This experiment demonstrates that both gene expression and neuronal morphology within the motor cortex can be altered as a function of motor experience. Given the behavioral complexity of motor skill and the anatomical complexity of the motor system, motor learning may well involve structural and functional changes distributed across several motor regions including the cerebellum (Floeter and Greenough, 1979; Pysh and Weiss, 1979; Black et al., 1990; Kleim et al., 1994), basal ganglia (Comery et al., 1995), and red nucleus (Tsukahara et al., 1981). Alterations in neuron structure and function through experience-induced patterns of modifications in gene expression is an attractive mechanism by which memory could be encoded within the brain.

\section{REFERENCES}

Agranoff BW, Davis RE, Brink JJ (1965) Memory fixation in the goldfish. Proc Natl Acad Sci USA 66:289-315.

Ambalavanar R, Van der Zee EA, Bolhius JJ, McCabe BJ, Horn G (1993) Co-expression of Fos immunoreactivity in protein kinase $(\mathrm{PKC} \gamma)$-positive neurones: quantitative analysis of a brain region involved in learning. Brain Res 606:315-318.

Anderson BJ, Eckburg PB, Relucio KI, Greenough WT (1992) Thickness of the motor cortex increases following 28 days of exercise or motor skill training. Soc Neurosci Abstr 18:346.

Anhokin K, Rose SPR (1991) Learning-induced increase of immediate early gene messenger RNA in the chick forebrain. Eur J Neurosci 3:162-167.

Anhokin K, Mileusnic R, Shamakina IY, Rose SPR (1991) Effects of early experience on c-fos gene expression in the chick forebrain. Brain Res 544:101-107.

Anker RL, Cragg BG (1974) Estimation of the number of synapses in a volume of nervous tissue from counts in thin sections by electron microscopy. J Neurocytol 3:725-735.

Bailey CH, Chen M (1983) Morphological basis of long-term habituation and sensitization in Aplysia. Science 220:91-93.

Bailey CH, Kandel ER (1993) Structural changes accompanying memory storage. Annu Rev Neurosci 16:397-426.

Bailey CH, Montarolo PG, Chen M, Kandel ER, Schacher S (1992) Inhibitors of protein and RNA synthesis block structural changes that accompany long-term heterosynaptic plasticity in Aplysia. Neuron 9:749-758.

Bialy M, Nikolaev E, Beck J, Kaczmarek L (1992) Delayed c-fos expression in sensory cortex following sexual learning in male rats. Mol Brain Res 14:352-356.

Black JE, Isaacs KR, Anderson BJ, Alcantara AA, Greenough WT (1990) Learning causes synaptogenesis whereas motor activity causes angiogenesis in cerebellar cortex of adult rats. Proc Natl Acad Sci USA $87: 5568-5572$.
Bourtchuladze R, Frenguelli B, Blendy J, Cioffi D, Schutz G, Silva A (1994) Deficient long-term memory in mice with a targeted mutation of the cAMP-responsive element-binding protein. Cell 79:59-68.

Bradley PM, Galal KM (1987) The effects of protein synthesis inhibition on structural changes associated with learning in the chick. Dev Brain Res 37:267-276.

Braendgaard H, Evans SM, Howard CV, Gundersen HJG (1990) Total number of neurons in human neocortex unbiasedly estimated using optical disectors. J Microsc 157:285-304.

Bullock S, Csillag A, Rose SPR (1987) Synaptic vesicle glycoproteins and acetylcholine levels in chick forebrain nuclei are altered by passive avoidance conditioning. J Neurochem 49:812-820.

Campeau S, Hayward M, Hope BT, Rosen JB, Nestler EJ, Davis M (1991) Induction of the c-fos proto-oncogene in rat amygdala during conditioned and unconditioned fear. Brain Res 565:349-352.

Castro-Alamancos MA, Borrell J, Garcia-Segura LM (1992) Performance in an escape task induces Fos-like immunoreactivity in a specific area of the motor cortex of the rat. Neuroscience 49:157-162.

Chang FLF, Greenough WT (1982) Lateralized effects of monocular training on dendritic branching in adult split-brain rats. Brain Res 232:283-292.

Chui R, Boyle WJ, Meek J, Smeal T, Hunter T, Karin M (1988) The c-fos protein interacts with the c-jun/AP-1 to stimulate transcription of AP-1 responsive genes. Cell 54:541-552.

Comery TA, Shah R, Greenough WT (1995) Differential rearing alters spine density on medium-sized spiny neurons in the rat corpus striatum: evidence for association of morphological plasticity with early response gene expression. Neurobiol Learn Mem 63:217-219.

De Togni P, Niman H, Raymond V, Sawchenko P, Verma IM (1988) Detection of Fos protein during osteogenesis by monoclonal antibodies. Mol Cell Biol 8:2251-2256.

Donoghue JP, Wise SP (1982) The motor cortex of the rat: cytoarchitecture and microstimulation mapping. J Comp Neurol 212:76-88.

Doubell TP, Stewart MG (1994) Short-term changes in the numerical density of synapses in the intermediate and medial hyperstriatum ventrale following one-trial passive avoidance training in the chick. J Neurosci 13:2230-2236.

Flexner JB, Flexner LB, Stella E (1967) Memory in mice as affected by intracerebral puromycin. Science 141:567-569.

Floeter MK, Greenough WT (1979) Cerebellar plasticity: modifications of Purkinje cell structure by differential rearing in monkeys. Science 206:227-229.

Greenough WT (1984) Structural correlates of information storage in the mammalian brain: a review and hypothesis. Trends Neurosci 7:229-233.

Greenough WT, Larson JR, Withers GS (1985) Effects of unilateral and bilateral training in a reaching task on dendritic branching of neurons in the rat motor-sensory forelimb cortex. Behav Neural Biol 44:301-314.

Greenough WT, Armstrong KE, Comery TA, Hawrylak N, Humphreys AG, Kleim JA, Wang X (1994) Plasticity related changes in synapse morphology. In: Cellular and molecular mechanisms underlying higher neural functions (Selverston AI, Ascher P, eds), pp 211-219. New York: Wiley.

Hall RD, Lindholm EP (1974) Organization of motor and somatosensory neocortex in the albino rat. Brain Res 66:23-38.

Hengerer B, Lindholm D, Heuman R, Ruther U, Wagner EF, Theonen H (1990) Lesion induced increase in nerve growth factor mRNA is mediated by c-fos. Proc Natl Acad Sci USA 87:3899-3903.

Heurteaux C, Messier C, Destrade C, Lazdunski M (1993) Memory processing and apamin induce immediate early gene expression in mouse brain. Mol Brain Res 3:17-22.

Jooss KU, Müller R (1995) Deregulation of genes encoding microfilament-associated proteins during Fos-induced morphological transformation. Oncogene 10:603-608.

Jorgensen MB, Deckert J, Wright DC, Gehlert DR (1989) Delayed c-fos expression in the rat hippocampus induced by transient global cerebral ischemia: an in situ hybridization study. Brain Res 484:393-398.

Keller A, Arissian K, Asanuma H (1992) Synaptic proliferation in the motor cortex of adult cats after long term thalamic stimulation. J Neurophysiol 68:295-308.

Kimura A, Caria MA, Melis F, Asanuma H (1994) Long-term potentiation within the cat motor cortex. NeuroReport 15:2372-2376.

Kleim JA, Napper RMA, Swain RA, Armstrong KE, Jones TA, Greenough WT (1994) Selective synaptic plasticity in the cerebellar 
cortex of the rat following complex motor learning. Soc Neurosci Abstr 20:1435.

Kleim JA, Ballard D, Vij K, Greenough WT (1995) The persistence of experience dependent morphological plasticity in the cerebellar cortex of the rat. Soc Neurosci Abstr 21:445.

Kuhl D, Kennedy TE, Barzilai A, Kandel ER (1992) Long-term sensitization training in Aplysia leads to an increase in the expression of BiP, the major protein chaperon of the ER. J Cell Biol 119:1069-1076.

Mileusnic R, Rose SPR, Tillson P (1980) Passive avoidance learning results in region specific changes in concentration of and incorporation into colchicine binding proteins in the chick forebrain. J Neurochem 34:1007-1015.

Morgan JI, Cohen DR, Hempstead JL, Curran T (1987) Mapping patterns of c-fos expression in the central nervous system after seizure. Science 237:192-197.

Patel SN, Stewart MG (1988) Changes in number and structure of dendritic spines $25 \mathrm{hr}$ after passive avoidance training in the domestic chick, Gallus Domesticus. Brain Res 449:34-46.

Pavlides C, Myashita E, Asanuma H (1993) Projection from sensory to motor cortex is important in learning motor skills in the monkey. J Neurophysiol 70:733-741.

Paylor R, Johnson RS, Papaioannou V, Speigelman BM, Wehner JM (1994) Behavioral assessment of c-fos mutant mice. Brain Res 651:275-282.

Pohle W, Ruethrich HL, Popov N, Matthies H (1979) Fucose incorporation into hippocampus structures after acquisition of a brightness discrimination. Acta Biol Med Ger 38:53-63.

Porter LL, Sakamoto K (1988) The organization and synaptic relationship of the projection from the primary sensory to the primary motor cortex in the cat. J Comp Neurol 271:387-396.

Pysh JJ, Weiss GM (1979) Exercise during development induces an increase in Purkinje cell dendritic tree size. Science 206:230-232.

Robertson HA (1992) Immediate early genes, neuronal plasticity and memory. Biochem Cell Biol 70:729-736.

Rose SPR (1989) Glycoprotein synthesis and postsynaptic remodeling in long term memory. Neurochem Int 14:299-307.

Rosenzweig MR, Krech D, Bennett EL, Diamond MC (1962) Effects of environmental complexity and training on brain chemistry and anatomy: a replication and extension. J Comp Physiol Psychol 55:429-437.
Sagar SM, Sharp FR, Curran T (1988) Expression of c-fos protein in brain: metabolic mapping at the cellular level. Science 240:1328-1331.

Sakamoto T, Porter LL, Asanuma H (1987) Long lasting potentiation of synaptic potentials in the motor cortex produced by stimulation of the sensory cortex in the cat: a basis for motor learning. Brain Res 413:360-364.

Sheng M, Greenberg ME (1990) The regulation and function of c-fos and other immediate early genes in the nervous system. Neuron 4:477-485.

Sterio DC (1984) The unbiased estimation of number and size of arbitrary particles using the physical disector. J Microsc 134:127-136.

Strick PL (1973) Light microscopic analysis of the cortical projection of the ventrolateral thalamic nucleus of the cat. Brain Res 55:1024.

Thompson RF (1986) The neurobiology of learning and memory. Science 233:941-947.

Tsukahara N, Oda Y, Notsu T (1981) Classical conditioning mediated by the red nucleus in the cat. J Neurosci 1:72-79.

Turner AM, Greenough WT (1983) Synapses per neuron and synaptic dimensions in occipital cortex of rats reared in complex, social or isolation housing. Acta Stereol [Suppl]2:239-244.

Turner AM, Greenough WT (1985) Differential rearing effects on rat visual cortex synapses. I. Synaptic and neuronal density and synapses per neuron. Brain Res 329:195-203.

Volkmar FR, Greenough WT (1972) Rearing complexity affects branching of dendrites in the visual cortex of the rat. Science 176:1445-1447.

Wise SP, Donoghue JP (1986) Motor cortex of rodents. In: Cerebral cortex (Jones EG, Peters A, eds), pp 243-270. New York: Plenum.

Withers GS, Greenough WT (1989) Reach training selectively alters dendritic branching in subpopulations of layer II-III pyramidals in rat motor-somatosensory forelimb cortex. Neuropsychologia 27:61-69.

Yi L, Greenough WT (1994) Enhancement of synaptic transmission induced by behavioral learning in rat motor cortex. Soc Neurosci Abstr 20:800.

Yin JCP, Wallach JS, Del Vecchio M, Wilder EL, Zhou H, Quinn WG, Tully T (1994) Induction of a dominant negative CREB transgene specifically blocks long-term memory formation in Drosophila. Cell 79:49-58

Yin JCP, Del Vecchio M, Zhou H, Tully T (1995) CREB as a memory modulator: induced expression of a dCREB2 activator isoform enhances long-term memory in Drosophila. Cell 81:107-115. 